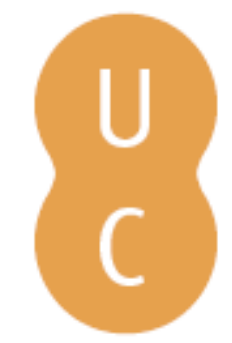

\title{
nommalina
}

\section{A simbologia da água e do fogo no párodo da Lisístrata de Aristófanes: uma encenação do grupo de teatro Thíasos}

Autor(es): $\quad$ Cação, Elisabete

Publicado por: Imprensa da Universidade de Coimbra

URL

persistente: URI:http://hdl.handle.net/10316.2/45101

DOI: $\quad$ DOI:https://doi.org/10.14195/978-989-26-1568-4_6

Accessed : $\quad$ 26-Apr-2023 11:08:10

A navegação consulta e descarregamento dos títulos inseridos nas Bibliotecas Digitais UC Digitalis, UC Pombalina e UC Impactum, pressupõem a aceitação plena e sem reservas dos Termos e Condições de Uso destas Bibliotecas Digitais, disponíveis em https://digitalis.uc.pt/pt-pt/termos.

Conforme exposto nos referidos Termos e Condições de Uso, o descarregamento de títulos de acesso restrito requer uma licença válida de autorização devendo o utilizador aceder ao(s) documento(s) a partir de um endereço de IP da instituição detentora da supramencionada licença.

Ao utilizador é apenas permitido o descarregamento para uso pessoal, pelo que o emprego do(s) título(s) descarregado(s) para outro fim, designadamente comercial, carece de autorização do respetivo autor ou editor da obra.

Na medida em que todas as obras da UC Digitalis se encontram protegidas pelo Código do Direito de Autor e Direitos Conexos e demais legislação aplicável, toda a cópia, parcial ou total, deste documento, nos casos em que é legalmente admitida, deverá conter ou fazer-se acompanhar por este aviso.

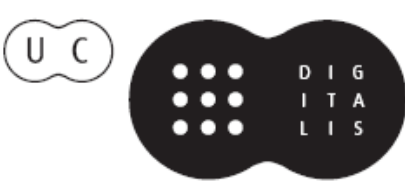




\section{O melhor é a água}

\section{Da antiguidade clássica aos}

nossos dias

José Luís Brandão \& Paula Barata Dias (coords.) 


\title{
A SIMBOLOGIA DA ÁGUA E DO FOGO NO PÁRODO DA LisísTR ATA DE ARISTÓFANES: UMA ENCENAÇÃO DO GRUPO DE TEATRO THÍASOS \\ (The Symbolism of Water and Fire in the Parodos of Lysistrata by Aristophanes. A staging of the Thiasos Theatre group)
}

\author{
Elisabete Cação (elisabetecacao@gmail.com) \\ Centro de Estudos Clássicos e Humanísticos ${ }^{1}$ \\ Universidade de Coimbra \\ orcid.org/0000-0002-5922-3765
}

\begin{abstract}
Resumo - Neste trabalho, pretendemos refletir sobre a simbologia da água e do fogo na peça "Lisístrata" de Aristófanes, sob a perspetiva da encenação levada a cabo durante a temporada 2012/2013 pelo grupo de teatro da Faculdade de Letras da Universidade de Coimbra, Associação Cultural Thíasos². Trabalhar um coro grego por si só é um obstáculo pelo o qual o encenador contemporâneo muitas vezes se vê constrangido, e é tarefa acrescida trabalhar as temáticas da "Lisístrata" sem cair no obsceno fácil e gratuito. A simbologia da água e do fogo deve ser associada à simbologia de cada género: água para o semicoro feminino, relacionada com trabalhos domésticos e com o interior da casa, e o fogo para o semicoro masculino, que desenvolve a ideia dos trabalhos fora de casa e, neste caso, muito especificamente à guerra. No entanto, o objetivo principal de Lisístrata é acabar com a Guerra do Peloponeso que opõe Atenienses e Espartanos, e que dura já há mais de 20 anos. Os métodos para a paz são ferozes mas utópicos, como se evidencia nas palavras do semicoro feminino, através da corifeia e sempre acompanhados de teor sexual: "Eu, com esta água, vim apagar o teu fogo" (v. 374). O semicoro masculino tenta sempre responder de acordo, mas mostra-se incapaz e sem força para suplantar o argumento feminino. $\mathrm{O}$ momento em que esta situação se revela mais evidente é no momento aquele em que a corifeia molha efetivamente o corifeu com a água que traz no cântaro.

Palavras-chave - Lísistrata, Água, Fogo, Párodo, Coro.
\end{abstract}

Aвstract - In this paper we aim to analyze the symbology of water and fire in the play "Lysistrata", based on the direction of the play by the theatre group Thíasos,

\footnotetext{
${ }^{1}$ Trabalho desenvolvido no âmbito da bolsa de doutoramento SFRH/BD/111097/2015, e do projeto UID/ELT/00196/2013, financiado pela FCT - Fundação para a Ciência e Tencologia.

${ }^{2}$ A Associação Cultural Thíasos é um grupo de teatro amador, formado por alunos e professores da Universidade de Coimbra, sobretudo da Faculdade de Letras. Acerca desta Associação, consulte-se bibliografia recente sobre o Festival de Teatro de Tema Clássico, que contará este ano [2013] com a XV edição. https://bdigital.sib.uc.pt/jspui/ handle/123456789/34.
} 
of the Faculty of Arts and Humanities of the University of Coimbra, in 2012/13. Working on a Greek chorus is by itself an obstacle that a director must face, and it is harder work when one has to deal with the thematic lines of a play such as "Lysistrata" without lapsing into easy laughter and obscenity. The symbology of water and fire must be associated with opposite genders: water for the feminine semi-chorus, linked to housework and the interior of the house, and fire for the masculine semi-chorus, linked to war and the outside of the house. Nevertheless, the main goal of Lysistrata is to end the Peloponnesian War, which opposes Greeks and Spartans, and it has lasted for over 20 years. The methods for peace are fierce but utopian, as in the words of the feminine semi-chorus, and they always have sexual content "And I've the water to put out your fire immediately" (v. 374). The masculine semi-chorus always tries to answer accordingly, but it shows himself incapable and without strength to overcome the feminine argument. The moment when it is more evident is when the old women's koryphaios actually wets the old men's koryphaios with the water of her vase.

Keywords - Lysistrata, Water, Fire, Parodos, Chorus

Em questões de interpretação dramática, consideramos ser mais fácil lidar com os problemas de uma encenação quando a colocamos em palco. As temáticas, o espaço, os diálogos tornam-se, de facto, mais vivos; a imaginação do encenador está mais alerta e disponível, assim como a disponibilidade dos atores para as cenas em representação, para uma maior harmonização final da peça, e com o sentido de que tenha, ainda hoje, significado. A propósito de uma peça como a Lisistrata, facilmente encontramos notícias de representações atuais, nos mais diversos meios, contextos e adversidades ${ }^{3}$. No entanto, dois panos de fundo são comuns: o tema da guerra e todas as lutas inerentes para acabar com ela; e o tema da greve de sexo, neste caso específico, para pôr fim, ainda que utopicamente, à Guerra do Peloponeso - noutras situações para combater obstáculos de outras naturezas: políticas, sociais, e de novo, militares ${ }^{4}$, mas sempre levadas a cabo por mulheres.

O contexto da Lisistrata é, portanto, o ambiente militar da Guerra do Peloponeso, conflito que decorria há sensivelmente duas décadas e que envolvia todo o mundo grego, numa disputa onde sobretudo se digladiavam Atenas e Esparta e os aliados de cada uma destas. De facto, nos anos anteriores a 411, data da estreia da Lisistrata, as batalhas travadas durante o período da Guerra do Peloponeso infligiram pesadas derrotas em ambos os exércitos, mas sobretudo no Ateniense. $\mathrm{Na}$ História da Guerra do Peloponeso de Tucídides, sobretudo nos livros dois a quatro, destacam-se, durante a primeira década de guerra, a chamada Guerra

\footnotetext{
${ }^{3}$ http://www.cerimonhouse.org/lysistrata-project-ten/. Consultado a 25 de janeiro de 2013.

${ }^{4}$ Uma pesquisa rápida na internet por 'sex strike' devolve-nos alguns acontecimentos marcantes: seja o caso da Colômbia em 1997 por questões sociais, da Libéria em 2003 por questões militares, ou no Togo em 2012 por questões políticas. http://en.wikipedia.org/wiki/ Sex_strike\#Modern_times
} 
Arquidâmica, as anuais invasões em território ático (Th. 2.10-12, 2.55-57,3.1, 4.2), a incursão em Potideia (Th. 2.70), a expedição e cerco de Plateias (Th. 2.71-78), as duas vagas de peste que assolaram Atenas em 429 e 427, a derrota naval contra a Acarnânia (Th. 2.81-82) e a situação de guerrilha na Messénia (Th. 4.9-23) ou ainda a derrota em Délio (Th. 4.89-96), até, finalmente, à conclusão da Paz de Nícias em 421 (Th. 5.15-20), que deveria durar os 50 anos nela estabelecidos, mas que apenas durou seis. Já durante a segunda década da Guerra, no livro cinco da mesma obra, as celebrações de alianças entre Atenas, Mantineia, Eleia e Argos que implicaram brechas na Paz de Nícias causaram incidentes diplomáticos com Esparta, culminando na batalha de Mantineia (Th. 5.64-73). Posteriormente, nos livros seis e sete, destaca-se ainda a forte intervenção de Alcibíades na política ateniense e a ruinosa expedição à Sicília (Th. 7.75-84), que contribuiu determinantemente para o enfraquecimento físico e moral dos Atenienses. É este enfraquecimento moral que perpassa nas peças aristofânicas com a temática da guerra, e é por esta razão que a utopia de Lisistrata é terminar a guerra de uma forma radical, com uma greve de sexo, para que o sofrimento causado por essa mesma guerra, de igual forma, termine também. ${ }^{5}$

$\mathrm{Na}$ abordagem que pretendemos fazer da peça, focar-nos-emos na análise da confrontação do coro, dividido em dois semicoros, um masculino e outro feminino, expressa, no párodo, pela simbologia da água e do fogo, e nas suas possibilidades de interpretação cénica, tendo em conta o trabalho que desenvolvemos no grupo de teatro Thíasos.

É consensual entre os estudiosos que toda a peça veicula informações contrárias à real e normal vivência do dia a dia das mulheres atenienses, que é, de resto, o que Aristófanes pretende valorizar: o cómico pela subversão ${ }^{6}$. Logo, é pelo menos comicamente real a possibilidade de imaginarmos as mulheres atenienses a celebrar um juramento de greve ao sexo, a convocar estrangeiras para esse mesmo juramento 7 , a tomar de assalto a Acrópole e, já no párodo, a enfrentar o semicoro masculino como se, politica e socialmente, tivessem direitos de cidadania iguais aos homens. $\mathrm{O}$ assalto à Acrópole pelas mulheres é mais um sinal de que os modelos de cómico na Lisístrata pretendem ilustrar o utópico dos planos doméstico e político da peça, correspondentes à impossibilidade de pôr fim à instabilidade social e de terminar a guerra, bem como do plano metafórico e cénico, no controlo que as personagens femininas detêm sobre a ação e sobre os personagens masculinos da peça - o semicoro feminino impor-se-á ao semicoro

${ }^{5}$ A Lisístrata não é, obviamente, peça única de temática de guerra. De Aristófanes, leia-se ainda Acarnenses de 425, Os Cavaleiros de 424 e Paz de 421.

${ }^{6}$ Vide Whitman 1964: 200-203; Dover 1972: 159; Henderson 1980: 190; Bowie 1993: 178-181; mas sobretudo Handerson 1987: xxx e sqq, cujo tema será desenvolvido adiante.

${ }^{7}$ Além de Lâmpito e Mírrina (de Esparta e Corinto), há ainda alusão a outras personagens, mudas, que na encenação acabámos por ter de cortar, por uma questão de economia de atores. 
masculino, Lisístrata ao Comissário, Mírrina a Cinésias, e a personificação feminina da Reconciliação a ambos os delegados Ateniense e Espartano.

Mas porquê uma greve de sexo? ${ }^{8}$ Durante situações de guerra, apesar de afastadas dos conflitos, as mulheres são vítimas dos acontecimentos, quer pela ausência, quer por morte dos maridos, como faz notar Lisístrata (vv. 102-104

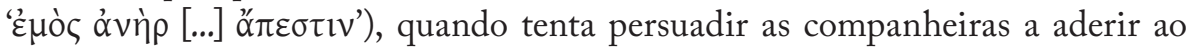

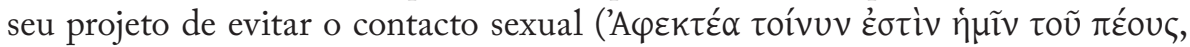
v. 124). Além disso, são também elas que administram a casa na continuada ausência dos maridos, o que lhes poderia conferir o poder de ajuizar decisões relativamente, também, à cidade, como faz Lisístrata, mais tarde na peça, com o Comissário (vv.507-528) e com os Delegados Espartano e Ateniense na celebração da $\mathrm{Paz}^{9}$ (vv. 1111-1135).

As quatro personagens iniciais (Lisístrata, Calonice, Mírrina e Lâmpito), bem como o semicoro feminino, são altivas, ainda que grosseiras, sobretudo na linguagem e no gesto. E, apesar da iniciativa de Lisístrata no sentido de obter a paz, os diálogos entre mulheres e homens são violentos e agressivos. A transição do prólogo para o párodo (vv. 240-251) é sublinhada pela fala de Lisístrata, quando anuncia a intervenção do coro de velhos com panelinhas e tochas, simbolicamente os seus escudos e armas. A necessidade de evidenciar a carga dos homens, sobretudo as tochas com o fogo aceso, é essencial para a contraposição com a entrada do coro de velhas com os seus próprios objetos associados ao feminino e à casa, neste caso, os cântaros com água ${ }^{10}$. Na nossa encenação, ambos os semicoros entram em cena, carregando esses objetos, o semicoro de velhos numa marcha processional e lenta, acompanhada da marcha fúnebre de Chopin, conotada na encenação com impotência e inaptidão masculina, por oposição à energia das mulheres, acompanhada de uma entrada desembaraçada com os cântaros, ao som da música "These boots are made for walking" de Nancy Sinatra. No entanto, nem personagens masculinos, nem personagens femininos denunciam o que eventualmente irá ocorrer: o confronto e sobreposição física da água sobre o fogo.

As portas da Acrópole são o nosso local de cena ${ }^{11}$, e é aí que se dá o confronto dos semicoros: as mulheres saem da Acrópole "porque ouviram dizer" que os

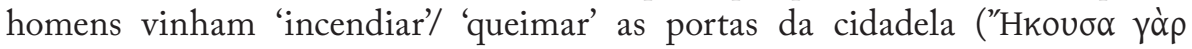

${ }^{8}$ Russo 1994: 166 afirma que "enclosure of women in Acropolis it's defending their sex-strike from men and securing themselves from men/ outside, which means war".

${ }^{9} \mathrm{Na}$ formulação da paz, nos últimos versos, entre o Delegado Ateniense e o Delegado Espartano, Lisístrata recorda, numa última tentativa, as intervenções cooperantes entre os dois lados antagonistas.

${ }^{10}$ Segal 1996: 146.

${ }^{11}$ Em palco, há uma placa sinalizadora em madeira, em português, que apontada para a direita indica o caminho para a Acrópole e virando-a para a esquerda aponta para a 'gruta de Pã', onde se dará a derradeira cena da greve de sexo, entre Mírrina e Cinésias. 


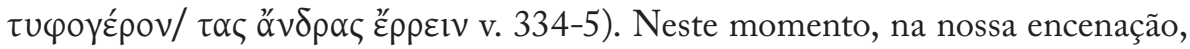
o semicoro de velhos não sabe das intenções da barricada das mulheres na Acrópole e pretende apenas restabelecer a ordem na cidade e terminar com a loucura das mulheres. Contudo, Russo ${ }^{12}$ nota que a novidade e a estranheza da parte do semicoro masculino resulta, antes, de ver sair da Acrópole um conjunto organizado de mulheres. Ao argumento de Russo, acrescentamos a ideia de que esta é uma situação estranha não porque não fosse comum as mulheres, juntas, carregarem cântaros de água para as suas tarefas domésticas, mas porque o semblante e o propósito com que saem da Acrópole e a forma como se dirigem ao coro de velhos não está de acordo com a caracterização tradicional das mulheres: recatadas nas tarefas domésticas e caladas sobre assuntos políticos.

Por um lado, quando o semicoro masculino toma conhecimento da barricada feminina, a intenção de acabar com esta fúria impiedosa das mulheres da tomada da Acrópole tornar-se-ia um acto corajoso, não fosse a passividade e fraqueza do semicoro masculino - a ideia principal que queremos passar. Por isso, na nossa encenação, o coro de velhos, depois de manifestar a sua intenção de chegar rápido à Acrópole, entoará quatro pequenos versos com a melodia inicial da Marcha Fúnebre de Chopin, para que o resultado seja o oposto, isto é, para que o incitamento da chegada rápida à Acrópole seja, na verdade, um movimento lento e de arrastamento dos velhos em dificuldade. Por outro lado, a subversão cómica, e até paradoxal, do párodo reside não só no assalto da Acrópole pelas mulheres com o objetivo único da paz, mas também no significado do método com que o fazem, uma vez que a postura feminina é agressiva: tomam uma atitude bélica para levar a cabo um propósito pacífico. Os motivos pacifistas engenhosos de Lisístrata são, numa leitura atenta, contrários aos ideais por eles veiculados ${ }^{13}$.

Mas analisemos agora a intervenção das mulheres no párodo. Segundo Maria de Fátima Sousa e Silva, ainda que no começo do canto, o texto de intervenção das mulheres faça referência a momentos de crise $^{14}$ - nomeadamente na relação entre o universo masculino ['campo de combate no exterior da cidade'] e o universo feminino ['dentro das muralhas [...] cenário da competição difícil por um cântaro de água' ] -, na conceção da peça, determinámos que o semicoro de velhas teria uma atitude completamente oposta à do semicoro de velhos: elas não se mostrariam, ao contrário dos seus adversários, vergadas ao peso da idade, como determinámos que seria o papel do semicoro de velhos durante a peça inteira; antes, deveriam mostrar-se enérgicas, mesmo se trapalhonas.

No que concerne a linguagem, de ambas as partes é agressiva, mas o lado

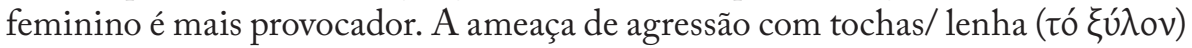

\footnotetext{
${ }^{12}$ Russo 1994: 167.

${ }^{13}$ Gilhuly 2009: 140-142. Na mesma linha, escreve Bowie 1993: 183.

${ }^{14}$ Sousa e Silva 2009: 288.
} 
por parte dos velhos é o ponto alto da provocação masculina, embora todas as suas tentativas saiam frustradas perante a reação das mulheres; se os homens tentam bater-lhes com as tochas, elas estão desimpedidas para dar resposta. É por esse motivo que, em palco, pousam os cântaros - símbolo da vitória feminina no final do

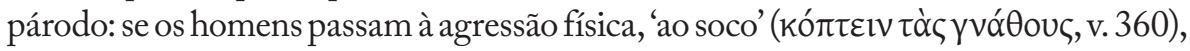

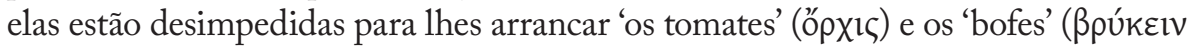

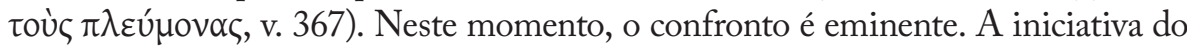

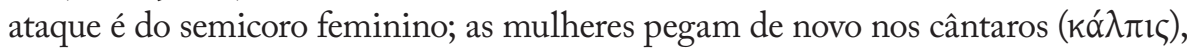
que ainda há pouco tinham largado, para se protegerem dos possíveis ataques dos velhos (v. 370). A partir deste momento, todo o agon entre o Corifeu e a Corifeia é construído tendo em vista o momento final e simbólico do triunfo das mulheres sobre os homens, isto é, metaforicamente da paz sobre a guerra, e literalmente da água sobre o fogo. $\mathrm{Na}$ encenação, tivemos o cuidado de reproduzir, de facto, este momento: quando os homens tomam as tochas ${ }^{15}$ para pegar fogo às mulheres numa pira ( dentro do cântaro, molha (óp $\rho \varepsilon ı v)$ efetivamente o Corifeu.

Segundo Henderson, 'toda a peça é um veicular de informações contrárias à real conduta das mulheres no quotidiano ateniense ${ }^{16}$, mas isso não quer dizer que tomemos por garantido que, porque as mulheres nesta peça circulam livremente no espaço público, devam relacionar-se com a figura das hetairai, como evidencia Gilhuly ${ }^{17}$. As hetairai devem ser deliberadamente postas de parte para que a greve ao sexo faça sentido ${ }^{18}$, uma vez que, com elas, o lado masculino teria garantido um acesso fácil ao sexo feminino. No entanto, devemos fazer uma leitura mais aprofundada da peça, não só a nível social, mas sobretudo a nível político. De acordo com Sega ${ }^{19}$, o papel das mulheres na Lisístrata deve ser lido em dois sentidos, tomando como referência a idade e a capacidade de intervenção das mulheres que acompanham Lisístrata: por um lado, devemos considerar primeiro a atuação do grupo de mulheres mais novas, que juram sobre o vinho executar o plano de Lisístrata; e por outro lado, o grupo de mulheres mais velhas, que compõem o coro e dão corpo à formação da barricada na Acrópole. Ambos

\footnotetext{
${ }^{15}$ As tochas usadas, embora apagadas durante as representações da peça por motivos de segurança dos edifícios, eram tochas de jardim altas, para que o efeito visual não diminuísse apesar de não haver qualquer forma de fumo ou fogo.

${ }^{16}$ Henderson 1987: xxv.

${ }^{17}$ Gilhuly 2009: 154.

18 Vide Henderson 1987: xxxiii e Dover 1972: 160. Concordamos com os autores quando explicam que devemos ignorar certos factos da vida real, como o caso de relações extraconjugais, para que o enredo da peça possa ter sentido. Neste caso, a ausência de relações sexuais conjugais é uma necessidade no enredo para dar sentido à greve de sexo formulada por Lisístrata no início da peça homónima.

${ }^{19}$ Segal 1996: 154 e ss.
} 
relacionam-se com os conceitos de política externa e interna, e juntos dariam sentido ao plano arquitetado por Lisístrata. Isto é, as mulheres mais novas são a base do conflito social, dentro da cidade, ao sustentarem o plano da greve ao sexo. Por esse meio, atraem o corpo masculino da peça para o espaço onde se decide a sanção a aplicar-lhe, o espaço público. Mas logo esse espaço é ocupado pelo grupo de mulheres mais velhas, que condiciona o acesso à Acrópole, mas, sobretudo, que bloqueia o acesso ao erário público onde o Comissário pretende chegar, de modo a poder financiar-se para a guerra. A dialéctica entre privado e público confunde-se e fica patente a ideia de que tanto a vida privada tem impacto na vida pública, como a vida pública na vida privada, pois uma atuação privada, como a vida conjugal, influencia a vida pública, ou assim o esperava Lisístrata com o seu plano, porque a vida pública, isto é, a situação da guerra, dominava todos os aspectos da vida privada.

É ainda possível fazer uma outra leitura em relação a Lisístrata, pela atuação deste coro feminino, a evocar um certo espírito masculino e guerreiro, que não é desprovida de valor mítico, se recordarmos mitos relacionados com os temas da ginecocracia, nomeadamente o das Amazonas e o das mulheres lémnias ${ }^{20}$. Neste último caso, Afrodite, irada com as mulheres de Lemnos, atormentou-as com um cheiro horrível que provocava o repúdio dos maridos. As Lémnias revoltaram-se e decidiram matar todos os homens da ilha. Contudo, Hipsípila não conseguiu matar o pai, o rei Toas, o único sobrevivente do massacre. A Lemnos, entretanto, chegou a nau Argo e, num festival, os Argonautas casaram-se com as mulheres locais, e Hipsípile com Jasão, de quem gerou dois filhos. Ainda assim, homens e mulheres, no final da festa, reúnem-se em casas separadas. Mais tarde no mito, as mulheres Lémnias descobrem que Hipsípile não matou o pai e, por isso, vendem-na como escrava ao rei Licurgo de Nemeia. Euneu, filho de Hipsípile e Jasão, purificou então a ilha de Lemnos com um ritual, durante o qual o fogo era apagado dos lares lémnios por nove dias, seguido de oferendas aos mortos e finalizado com a aportação de um barco, com novo fogo, do altar de Apolo em Delos.

Ainda que água e fogo, elementos primordiais da natureza, sejam por si só um símbolo de feminino e masculino respectivamente, na peça Lisístrata ganham novo significado social e político, nomeadamente na construção das dicotomias masculino/ feminino, público/ privado. Na nossa encenação, na parte do párodo, tentámos recriar o mais possível a simbologia da ausência do fogo relacionada com a inatividade masculina, e a supremacia feminina através da água, ilustrando-a quer com momentos musicais, apropriados à disposição de cada semicoro, quer com a própria ocupação do palco por ambas as partes, que propositadamente dará mais relevo ao coro feminino e às suas preocupações.

\footnotetext{
${ }^{20}$ Bowie 1993: 186 e ss.
} 
Resta mencionar que a gravação da ante-estreia da peça, no dia 29 de Abril de 2013, no teatro Paulo Quintela da Faculdade de Letras da Universidade de Coimbra, está disponível online em:

https://drive.google.com/open?id=0B8q-K0-QNJZiQmprMmREZT16N2c

\section{BibliografiA}

Bowie, A. M. (1993), Aristophanes. Myth, ritual and comedy. Cambridge University Press.

Cambridge Ancient History (1969), Bury, J. B., Cook, S. A., Adcock, F. E. (eds.), Volume 5 'Athens: 478-401 B.C.'. Cambridge University Press.

Dorati, M. (1999), "Acqua e fuoco nella Lisistrata”, Quaderni Urbinati di Cultura Classica 63.3: 79-86.

Dover, K. J. (1972), Aristophanic Comedy. Berkeley and Los Angeles, University of California Press.

Gilhuly, K. (2009), The Feminine Matrix of Sex and Gender in Classical Athens. Cambridge University Press.

Henderson, J. (1980), “Lysistrate: the play and its themes”, in Henderson, J. (ed.), Aristophanes: Essays in Interpretation, Yale Classical Studies, volume XXVI. Cambridge University Press.

Henderson, J. (1987), Aristophanes' Lysistrata. Oxford Clarendon Press.

Martin, R. (1987), "Fire on the mountain: 'Lysistrata' and the Lemnian Women”, Classical Antiquity 6.1: 77-105.

Ribeiro Ferreira, J., Leão, D. (2010), Dez Grandes Estadistas Atenienses. Lisboa, Edições 70 .

Rosado Fernandes, R., Granwher, M. G. P. (2010), Tucídides. História da Guerra do Peloponeso, Trad. do texto grego, prefácio e notas introdutórias. Lisboa, Fundação Calouste Gulbenkian.

Russo, C. F. (1994), Aristophanes, an author for the stage. London, Routledge.

Segal, E. (ed.) (1996), Oxford Readings in Aristophanes. Oxford University Press.

Sousa e Silva, M. F. (2009), "Sexo e sociedade: a Lisistrata de Aristófanes", in J. A. Ramos, M. C. Fialho, N. S. Rodrigues (coords), A Sexualidade no Mundo Antigo. Porto, Centro de História da Universidade de Lisboa, Centro de Estudos Clássicos e Humanísticos da Universidade de Coimbra: 279-291.

Sousa e Silva, M. F. (2010), Aristófanes. Comédias II.Lisboa, INCM.

Whitman, C. (1964), Aristophanes and the Comic Hero. Harvard University Press. 